\title{
A violência simbólica: o Estado e as práticas sociais
}

José Vicente Tavares do Santos

\section{(2) OpenEdition}

\section{Journals}

Edição electrónica

URL: http://journals.openedition.org/rccs/6169

DOI: $10.4000 /$ rccs.6169

ISSN: 2182-7435

\section{Editora}

Centro de Estudos Sociais da Universidade de Coimbra

Edição impressa

Data de publição: 1 dezembro 2015

Paginação: 183-190

ISSN: 0254-1106

\section{Refêrencia eletrónica}

José Vicente Tavares do Santos, «A violência simbólica: o Estado e as práticas sociais », Revista

Crítica de Ciências Sociais [Online], 108 | 2015, posto online no dia 16 dezembro 2015, consultado o 21 dezembro 2020. URL : http://journals.openedition.org/rccs/6169; DOI : https://doi.org/10.4000/rccs. 6169

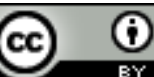




\title{
Revisões críticas
}

\section{A violência simbólica: o Estado e as práticas sociais}

\author{
Revisão de Bourdieu, Pierre (2012), Sur l'État. Cours au Collège de France (1989-1992). \\ Paris: Raisons d'Agir/Seuil, 672 pp.
}

Pierre Bourdieu situa-se em uma região do campo intelectual da sociologia contemporânea que poderia ser denominado de pós-estruturalismo crítico, ótica que procura situar os conflitos tanto a nível micro- quanto a nível macrossocial, tentando superar tal antinomia.

Concebe a sociedade como formada por grandes conjuntos, os quais são modificados por grupos, classes e categorias sociais; e a sociedade, por sua vez, também modifica a estes agentes sociais.

Esta seria a sociologia dos campos, dos diferentes capitais e do habitus, de Pierre Bourdieu. A teoria dos campos reconhece a pluralidade de mundos sociais, os diferentes capitais a estruturar cada campo e a compreensão da dinâmica inter-relacional entre as estruturas objetivas e as estruturas mentais nas sociedades modernas e contemporâneas. O modo de trabalhar parte de uma epistemologia pós-cartesiana que supera o ensaísmo teoricista e o empirismo realista, do racionalismo aplicado de Gaston Bachelard (Bourdieu et al., 1973). Trata-se de um racionalismo realista, uma filosofia do saber, da racionalidade e do conceito. Critica o positivismo na Sociologia, percebendo as alterações da cientificidade na primeira metade do século $\mathrm{xx}$, e da ideia reificada do social; daí utilizar o conceito de ruptura epistemológica.

Salienta que a sociologia da sociologia deve ser uma tarefa permanente: a sociologia do conhecimento sociológico caminha pela arte da invenção, localizando a sociologia em uma posição meta-meta no espaço social (Bourdieu, 2012: 94). Inicia seu trabalho de construção do objeto pela crítica às pré-noções, as ideias recebidas e a sociologia espontânea, salientando a necessidade de uma definição provisória do objeto, sempre trabalhando com hipóteses. Concebe os métodos e técnicas como teorias em ato. Adiciona uma referência à análise do discurso: "A análise do discurso que estuda o discurso sem estudar as condições sociais de produção do discurso não compreende nada" (ibidem: 32).

Retoma Bachelard: O fato social é conquistado depois constatado, contra a doxa (ibidem: 171-173). E salienta: "Uma das armas da crítica é confrontar um regime com sua verdade oficial para mostrar que ele não é conforme ao que diz" (ibidem: 65). Concebe a sociologia como "uma maneira de construir a realidade que permite ver os fatos que, normalmente, não são vistos"(ibidem: 96). E define: "Minha estratégia constante é de abarcar os grandes problemas por um lado acessível onde eles mostram o essencial que se esconde sob as aparências do insignificante" (ibidem: 142). Vai realizar o modelo teórico de um processo: "um conjunto de proposições sistematicamente ligadas e justificáveis de uma verificação sistemática, suscetível de dar conta de um conjunto de fatos históricos tão grande quanto possível" (ibidem: 170). 
Bourdieu propicia o rigor dos processos científicos de construção do objeto de investigação, fornece a demonstração detalhada, multivariada, da realidade social, e, em uma postura definida como um pós-estruturalismo genético, reorienta o olhar do sociólogo para uma perspectiva relacional.

Dispomos, por meio desta ótica que toma como primado as relações sociais, e não as entidades sociais, uma possibilidade analítica na reconstrução dos espaços das posições sociais, mediante a qual as classes, as frações de classe e os grupos sociais e culturais elaboram práticas de reprodução social, através das formações de habitus e de trajetórias de reprodução e de reconversão. Podemos, agora, percorrer seus principais conceitos.

Sua postura da ciência é a construção de um habitus científico, bem como sua disseminação. O babitus científico baseia-se em alguns momentos: na ruptura epistemológica; na vigilância epistemológica; e na construção do objeto. Afirma o pluralismo de métodos de investigação que vão ser orquestrados a partir da orientação da pesquisa. $\mathrm{O}$ autor situa-se em uma ética de combate à injustiça, de combate à desigualdade e às discriminações e racismos, atitude que aparece dispersa em sua obra (Bourdieu, 2002).

No final do livro La noblesse d'État, fala sobre o poder do Estado, o campo do poder, composto pela articulação de estruturas mentais e estruturas objetivas (Bourdieu, 1989a). Escreve ser possível que essas relações de força no campo do poder, essas lutas entre dominantes, façam necessariamente entrar no campo do poder um pouco do universal - a razão, o desinteresse, o civismo, etc. -, uma arma sempre simbolicamente eficaz nas lutas do momento. Talvez não só os dominados possam tirar partido dos conflitos entre os dominantes, como também talvez essas lutas entre os dominantes no momento em que permitem ou necessitam de fazer apelo ao universal façam com que esse universal apareça como possibilidade histórica. No campo simbólico, constituído por maneiras de ver e de pensar, dá-se a produção social da violência simbólica. Bourdieu assim a define: "A violência simbólica é uma violência que se exerce com a cumplicidade tácita daqueles que a sofrem e também, frequentemente, daqueles que a exercem na medida em que uns e outros são inconsciente de a exercer ou a sofrer" (Bourdieu, 1996: 16). Neste livro mais recente: "O que denomino de violência simbólica ou dominação simbólica, ou seja, formas de coerção que se baseiam em acordos não conscientes entre as estruturas objetivas e as estruturas mentais" (Bourdieu, 2012: 239).

Segundo Bourdieu, "o Estado é a posse do monopólio da violência física e simbólica": “[...] O Estado é o que funda a integração lógica e a integração moral do mundo social e, por aí, o consenso fundamental sobre o sentido do mundo que é a condição mesma dos conflitos a propósito do mundo social" (ibidem: 15). Daí sua afirmação de um golpe de força simbólica na gênese do Estado: "O golpe de Estado do qual nasceu o Estado [...] testemunha um golpe de força simbólico extraordinário que consiste em fazer aceitar universalmente, nos limites de um certo território..., a ideia de que todos os pontos de vista não são válidos e que há um ponto de vista que é a medida de todos os pontos de vista, dominante e legítimo" (ibidem: 116).

Por consequência, o Estado é a base das classificações sociais: "Uma das funções mais gerais do Estado é a produção e a canonização das classificações sociais" (ibidem: 24). Isso se verifica na produção das estatísticas, sistema de ensino (ibidem: 27) e do sistema linguístico (ibidem: 113), incluindo a ortografia (ibidem: 194). Trata-se de "categorias legítimas, um nomos, 
um princípio de divisão universalmente reconhecido nos limites de uma sociedade" (ibidem: 24).

Dois outros exemplos da centralidade do Estado são mencionados: o mercado da casa individual (Bourdieu, 1993; Bourdieu, 2000) - "O problema público é um problema que merece ser tratado publicamente, oficialmente" (Bourdieu, 2012: 30 e 47) - e o trabalho das Comissões "Essas comissões públicas são encenações, operações consistindo a desempenhar algo como um drama público, o drama da reflexão sobre os problemas públicos" (ibidem: 48 e 62).

Menciona a obra de Kafka, na construção de uma utopia na qual cada um poderia exercer seu direito de julgar e de se julgar, mas que encontra um obstáculo em um Estado que condensa o centro da vida social, sendo "a última instância à qual se pode recorrer" (ibidem: 114, 324, 328). O Estado seria uma comunidade ilusória, um consenso último (ibidem; 28). Daí sua tese principal: o Estado é um campo, um campo de poder, um campo administrativo como setor particular deste.

A questão central do livro é como fazer uma genealogia histórica ou estrutural (ibidem: 144). Podemos reconstruir seus procedimentos, desde a construção do caso, pois é preciso "tratar um caso particular, mas o constituindo, segundo a fórmula de Bachelard, como um caso particular de possíveis..." (ibidem: 143). Seu preceito metodológico é "abarcar um caso particular do qual não se conhece a particularidade mais no qual se poderia ver o modelo - à condição de não esquecer a particularidade (ibidem: 217). Partindo da Idade Média, vai analisar os exemplos inglês, francês e japonês (ibidem: 29). Em seguida, vai descobrir as lógicas práticas e a gênese das estruturas individuais e das estruturas sociais, recorrendo ao conceito de babitus (ibidem: 153-154). Desenvolve novamente a teoria dos campos: o campo é um "espaço estruturado segundo oposições ligadas a formas de capital específicos, com interesses diferentes" (ibidem: 40). As propriedades do campo são: estrutura do espaço objetivo, divisões, forças e agentes. Porém, existem situações de emergência nas quais se realizam saltos qualitativos (ibidem: 130), havendo mesmo um retorno à incerteza (ibidem: 186).

Sublinha a estrutura e os agentes sociais que o conformam: "A gênese do Estado é a gênese de um lugar de gestão do Universal, e ao mesmo tempo, de um monopólio do Universal, e de um conjunto de agentes que participam do monopólio de fato desta coisa que, por definição, é do universal" (ibidem: 60, 165). Salienta o papel dos juristas (ibidem: 95, 97-99): "Há um certo número de agentes sociais - entre os quais os juristas - que desempenharam um papel eminente, em particular os detentores deste capital de recursos organizacionais que era o direito romano" (ibidem: 60).

Estabelece algumas distinções: entre Estado e sociedade civil - "a ideia de um continuum que é uma distribuição contínua dos recursos coletivos, públicos, materiais ou simbólicos, aos quais se associa o nome do Estado" (ibidem: 66). Desta distribuição nascem as lutas políticas.

Realiza uma crítica a uma série de historiadores e sociólogos: Perry Anderson, Theda Skocpol, Reinhard Bendix, Barrington Moore, Eisenstadt, Marc Bloch, Gerschenkron e Michael Mann. Propõe uma abordagem capaz de apreender o processo de criação permanente de transformação das estruturas, presente tanto na objetividade do mundo social quanto na subjetividade dos agentes sociais.

No Curso proferido no dia 17 de janeiro de 1991, há quatro movimentos teóricos:

1. Análise genética do nascimento do Estado (Bourdieu, 2012: 195). 
2. Menção ao fetiche do Estado: "o Estado é um poderio simbólico" (ibidem: 196);

3. Referência a um território do Estado: "[...] A construção do Estado como campo relativamente autônomo exercendo um poder de centralização da força física e da força simbólica, e constituindo assim um embate de lutas, é inseparavelmente acompanhado pela construção de um espaço social unificado que lhe serve de base" (ibidem: 197).

4. Menciona os critérios para identificar sociologicamente os Agentes Sociais: selecionar os agentes pertinentes ao problema; identificar as propriedades pertinentes do campo; e construir a estrutura do espaço objetivo (ibidem: 38).

Bourdieu faz referência aos agentes sociais, formulando as seguintes perguntas: "Quem tem interesse no Estado? Existem interesses do Estado? Há interesses do público, do serviço público? Há interesses universais e quem são seus portadores? Quem tem os monopólios dos monopólios do Estado - violência física e simbólica legítimas?" (ibidem: 199). Nesse sentido, vai analisar "[...] o processo de construção do Estado e os responsáveis deste processo de construção" (ibidem).

A revisão de Norbert Elias inicia pelo reconhecimento da sua teoria genética do Estado de inspiração weberiana, salientando a menção de Weber do monopólio legítimo da violência física e do imposto. Trata-se da concentração progressiva dos instrumentos de violência, pois "O monopólio dos recursos originados pelo imposto permitem assegurar o monopólio da força militar permitindo a manutenção da força do imposto" (ibidem: 205).

Em outras palavras, se trataria de uma extorsão legítima (ou crime organizado), uma vez que a monopolização é uma série de disputas eliminatórias em cujo final um dos concorrentes desaparece, pois a dominação do Estado supõe uma forma de paz (ibidem: 206-207). Outro processo é a constituição de uma "rede de interdependência de poderosos detentores de princípios de poderio diferentes" (ibidem: 209).

A crítica feita por Bourdieu vai no sentido de Elias perder a dimensão simbólica do poder estatal (ibidem: 204): tanto Elias como Weber não esclarecem quem detém o monopólio da violência legítima (ibidem: 365).

Assinala que Charles Tilly identifica três vias no processo de formação do Estado: a trajetória capitalista, ou a lógica econômica da acumulação de capital e as cidades; a trajetória coercitiva, ou a concentração dos instrumentos de coerção; e a trajetória mista (ibidem: 212-214).

$\mathrm{Na}$ análise da obra de Corrigan e Sayer, mesmo reconhecendo sua importância ao salientar que o Estado é um conjunto de formas culturais, critica seu esquecimento das formas de violência física e do capital econômico na formação do Estado (ibidem: 225).

Bourdieu desenvolve a construção de uma sociologia reflexiva: uma sociologia reflexiva é basicamente uma explicação sistemática e relacional do mundo social. Por sistemática, implica que ela vai estar sempre preocupada em discutir os seus instrumentos de conhecimento, a sociologia é inseparável da sociologia de uma sociologia - a vigilância epistemológica de Gaston Bachelard.

Em Le métier de sociologue (Boudieu et al., 1973), o autor se referia a Gaston Bachelard, retomando a ideia da reflexibilidade, "um pensamento que está sempre se debruçando sobre si próprio, analisando suas condições sociais de produção e de objetivação; e, ao mesmo tempo, um pensamento que é relacional" - o modo de pensamento 
que é relacional e analógico que é favorecido pelo conceito de campo permite apreender a particularidade no interior $\mathrm{da}$ generalidade e vice-versa. Em outras palavras, "um caso particular bem construído deixa de ser um caso particular".

Decorre daí a ideia de que qualquer metodologia pode ser usada, mas exige um tempo de partir de uma condição de rigor: a crítica reflexiva das técnicas e dos procedimentos, buscando em Bachelard a noção de que toda a técnica é uma teoria em ato. Conclui por ser contra o fanatismo e a cegueira fetichista que trabalha nas ciências sociais: quando ela desvela os fundamentos históricos e os determinantes sociais dos princípios de hierarquia e de avaliação que devem sua eficácia simbólica ao fato de que elas vivem e se impõem como absolutos universais e eternos. A ciência social tem essa função de desvelar o absoluto, de relativizar o universal e de desencantar o eterno.

Neste Bourdieu, que aparece tão estrutural, tão rigoroso e tão objetivo, no fundo tem uma preocupação, datando dos anos de 1990, quiçá mesmo antes, com o que chamava do sofrimento de uma nova espécie e injustiça de uma nova ordem. O autor acredita no "utopismo sociológico" que, longe de ser um utopismo racional e longe de ser uma ciência sem utopia, constituiria exatamente o conjunto das condições de possibilidades dadas por um desvelamento rigoroso do mundo social, o que permitiria uma liberdade a partir do próprio conhecimento sociológico das condições sociais de produção da sociedade e de produção do conhecimento sobre a sociedade.

Há uma lógica da pesquisa no Homo academicus (e no segundo capítulo do Poder simbólico, 1989b) representada pela aventura, uma navegação: "somente quem não fez pesquisa empírica não sabe que nós caminhamos às vezes às cegas, mas é caminhando às cegas que um dia nós podemos saber o significado que tais materiais tiveram, ou têm, ou podem ter".

Se o sociólogo somente procurar a clareza teoricista, jamais fará pesquisa porque nunca vai se permitir a ousadia do desconhecido: o sociólogo realiza a travessia entre o conhecido e o desconhecido. Cabe, então, uma crítica ao "professoral", ao que está pronto, ao narcisismo intelectual da reprodução do conhecimento sem tensionar o saber. Daí a opção pela angústia da pesquisa.

Há uma tentativa de superar, por um lado, o teoricismo, essa teoria que tudo quer explicar de um modo absolutamente racional e conceitual, mas que nada ousa superar; e, por outro, de superar os procedimentos rigorosos de uma pesquisa ou de uma suposta metodologia de pesquisa que tudo prova, mas nada ousa. A superação dessa antinomia marca sua obra, uma vontade de superar a antinomia entre teoria e pesquisa, entre indivíduo e sociedade, entre estrutura e ação.

Afirma que a pior coisa do mundo são os professores, no fundo a história escolástica, essa busca obsessiva do rigor absoluto, a busca da perfeição, o que é sempre uma projeção da sua própria incapacidade.

Salienta que há um certo número de falsos debates, mortos e enterrados (externo e interno, qualitativo e quantitativo, etc.), que podem ser superados pela exigência rigorosa de uma reflexibilidade, o que vai chamar de lógica da pesquisa: aprender a pesquisa como uma atividade racional, não como uma espécie de busca mística, mas que também tem o efeito de aumentar a angústia. Essa postura realista está orientada para a maximização do rendimento do investimento e para o melhor aproveitamento do recurso a começar pelo tempo que se dispõe. O que interessa é ver a síntese em status nascendi, contrariamente a esse homo academicus que gosta do acabado. 
Entretanto, percebo que podem ser feitas algumas críticas a esta importante obra:

1. há escassa menção ao papel da Polícia (Bourdieu, 2012: 22), sobre a força (p. 302) ou a força pública (p. 314);

2. escassez de referência ao papel dos Exércitos e das guerras na construção do Estado;

3. não menciona os agentes econômicos no processo;

4. transforma a violência simbólica em determinação em última instância: "Para mim, o capital simbólico é o fundamento" (Bourdieu, 2012: 327);

5. minimiza a contribuição de Michel Foucault (ibidem: 566); e

6. apenas efetiva uma breve alusão ao romance policial, no qual o comissário e o juiz sempre seriam agentes do Estado (ibidem: 581).

Neste livro tardio reafirma: "Trata-se de reconstruir as operações de construção que os agentes sociais operam para construir suas interações ou relações..." (ibidem: 51). Está buscando uma causalidade estrutural ou uma gênese histórica dos problemas (ibidem: 50), marcada pela historicidade: é a construção das realidades do mundo e das categorias que explicam as realidades do mundo - a multidimensionalidade das práticas e dos modelos históricos.

Ao mesmo tempo, adota a postura relacional de Bachelard: a relação explica o ente, razão pela qual sempre criticou a noção substancialista de classe social, seja em Marx, reificada, seja em Weber, reduzida à situação de classe na órbita do mercado. Por outro lado, assume uma orientação construtivista, pois a noção de categoria é um "princípio coletivo de construção da realidade coletiva" (Bourdieu, 1994: 137): as categorias existem "como instituições [...] e na objetividade do mundo, sob a forma de corpos sociais" e "nos espíritos, sob a forma de princípios de classificação" (ibidem: 143).
Pierre Bourdieu propicia o rigor dos processos científicos de construção do objeto de investigação, fornece a demonstração detalhada, multivariada, da realidade social, e, em uma postura definida como um pós-estruturalismo genético reorienta o olhar do sociólogo para uma perspectiva relacional.

Dispomos de uma ótica que toma como primado as relações sociais, e não as entidades sociais; aparece uma possibilidade analítica na reconstrução dos espaços das posições sociais, mediante a qual as classes, as frações de classe e os grupos sociais e culturais ou as categorias sociais elaboram práticas de reprodução social, através da formação de babitus e de trajetórias de reprodução e de reconversão.

A teoria dos campos reconhece a pluralidade de mundos sociais, os diferentes capitais a estruturar cada campo e a compreensão da dinâmica inter-relacional entre as estruturas objetivas e as estruturas mentais nas sociedades contemporâneas, uma análise pela ótica da conflitualidade. A ciência rigorosa do social poderia possibilitar a sociologia dos determinantes sociais da prática sociológica como o único fundamento possível de uma liberdade possível em relação a essas determinações.

Estes seriam o utopismo sociológico, um utopismo racional, ou o uso politicamente consciente e racional dados pelo conhecimento das leis sociais e especialmente de suas condições históricas de validade. A tarefa política seria trabalhar e definir um utopismo racional, usando o conhecimento provável para fazer vir o possível, em um uso ético da sociologia reflexiva. Encontraríamos, então, uma reconciliação do scholarship e do commitment. Uma lição aos jovens leitores.

José Vicente Tavares dos Santos 


\section{Referências bibliográficas}

Bourdieu, Pierre (1984), Homo academicus. Paris: Minuit.

Bourdieu, Pierre (1989a), La noblesse d' État. Grandes écoles et esprit de corps. Paris: Minuit.

Bourdieu, Pierre (1989b), O poder simbólico. Lisboa: Difel.

Bourdieu, Pierre (org.) (1993), La misère du monde. Paris: Seuil.

Bourdieu, Pierre (1994), Raisons pratiques. Sur la théorie de l'action. Paris: Seuil.

Bourdieu, Pierre (1996), Sur la télévision. Paris: Liber.

Bourdieu, Pierre (2000), Les structures sociales de l'économie. Paris: Seuil.

Bourdieu, Pierre (2002), Interventions, 1961-2001 - Sciences sociales et action politique. Marseille: Agone.

Bourdieu, Pierre (2012), Sur l'État. Cours au Collège de France (1989-1992). Paris: Raisons d'Agir/Seuil.

Bourdieu, Pierre; Chamboredon, Jean-Claude; Passeron, Jean-Claude (1973), Le métier de sociologue. Paris: Mouton [2. ${ }^{a}$ ed.].

\section{José Vicente Tavares do Santos}

Diretor do Instituto Latino-Americano de Estudos Avançados da Universidade Federal do Rio Grande do Sul Av. Bento Gonçalves, 9500 Prédio 43322 - Agronomia - Campus do Vale 91509-900 - Porto Alegre, RS - Brasil

Contacto: jvicente@ufrgs.br 
